\title{
Strength and Autogenous Shrinkage of High Strength Mortar Using Water Substituting Liquid
}

\author{
Han, Min-Cheol Lee, Dong-Gyu* \\ Department of Architectural Engineering, Cheong ju University, Naedoekdong, Cheongju si, 360 170, Korea
}

\begin{abstract}
This paper is to experimentally investigate the strength and autogenous shrinkage of high strength mortar with the $20 \%$ of water binder ratio(W/B). In this study, the water substituting liquid(WSL) was used including gasoline, light oil, lamp oil, edible oil, HFE, ethanol, methanol and acetone in order to explore changes in strength and autogenous shrinkage depending on WSL type and replacement. For fresh properties, the replacement of WSL did not affect the fluidity of mortar mixtures considerably, except for ethanol and methanol. However, the replacement of WSL resulted in a slight decrease in flexural and compressive strength. For autogenous shrinkage, the replacement of WSL led to reduce autogenous shrinkage, and especially, the replacement of edible oil led to reduce autogenous shrinkage significantly due to saponification between edible oil and cement.
\end{abstract}

Keywords : high strength concrete, water substituting liquid, strength, autogenous shrinkage

\section{Introduction}

Contemporary buildings have become higher and larger in size due to overpopulation and integration of facilities. The buildings should be durable and economical so that effective construction materials are usually used like high strength concrete. Super high-rise buildings and super long span bridges have brought such materials that help mitigate dead weight and improve durability of structures in demand. For this reason, a lot of research has been conducted[1,2].

The lower the water/cement ratio (W/C) is, the higher cement strength becomes. Since excessive use of superplasticizer can bring about concrete degradation, the use of water is indispensible[3,4]. As high strength concrete is generally used in a

Received : June 2, 2011

Revision received : October 21, 2011

Accepted : October 25, 2011

* Corresponding author : Lee, Dong-Gyu

[Tel:+82-043-229-7861, E-mail: scarllet2002@naver.com]

(c)2011 The Korea Institute of Building Construction, All rights reserved. large quantity in the field, hydration of cement causes drying and autogenous shrinkage, which leads to cracks and deformation and greatly reduces the durability of the structure in the end[5].

There are few studies conducted to decrease the W/C by using water substituting liquid instead of reducing the amount of mixing water, and lower autogenous shrinkage and improve the performance of high strength concrete[6].

Therefore, this paper aims to ultimately verify the possibility of improving the performance of high strength mortar by analyzing the effect of WSL on the strength and autogenous shrinkage based on the high strength mortar produced by replacing some of the mixing water with water substituting liquid (not water but volatile or hydraphobic liquid, hereinafter referred to as WSL).

\section{Experimental plan and method}

\subsection{Experimental plan}

Table 1 shows the experimental plan for this 
study, and Table 2 illustrates the mixture proportions of mortar.

Table 1. Experimental plan

\begin{tabular}{|c|c|c|c|}
\hline & Factors & & els \\
\hline & $\mathrm{W} / \mathrm{B}(\%)$ & 1 & 20 \\
\hline & $C: S$ & 1 & $1: 1$ \\
\hline & $\begin{array}{c}\text { Binder } \\
\text { composition }\end{array}$ & 1 & $\mathrm{OPC}(7): F A(2): S F(1)$ \\
\hline & Target Flow $(\mathrm{mm})$ & 1 & $220 \pm 10$ \\
\hline Mivt & & & - Plain · P( 10) \\
\hline IVIIxture & & & · Gasolıne · Light oll \\
\hline & Types of WSL & 10 & · Lamp oil · Edible oil \\
\hline & & & $\cdot \mathrm{HFE}^{1)} \cdot$ Ethanol \\
\hline & & & - Methanol · Acetone \\
\hline & $\begin{array}{c}\text { Replacement } \\
\text { ratio of } \\
\text { WSL }(\% / w)\end{array}$ & 3 & $0,10,20$ \\
\hline & Fresh mortar & 1 & Flow \\
\hline Experi & & & $\begin{array}{l}\text { - Compressive strength } \\
(1,7,28 \text { days })\end{array}$ \\
\hline -ment & Hardened mortar & 3 & - Flexural strength(1, 28 days) \\
\hline & & & - Autogenous shrinkage \\
\hline
\end{tabular}

1) $\mathrm{HFE}\left(\mathrm{C}_{4} \mathrm{~F}_{9} \mathrm{OCH}_{3}\right)[7]$ :Liquid for washing electronic product instead of water 2) $\mathrm{P}(-10)$ : water reduced mix by $10 \%$ compared with plain mix

Table 2. Mixture proportions of mortars

\begin{tabular}{|c|c|c|c|c|c|c|c|c|c|}
\hline \multirow{2}{*}{ Mixtures } & \multirow{2}{*}{\multicolumn{3}{|c|}{$\begin{array}{c}\text { WSL } W / B_{-} \\
\text {C:S }(\% / d) \\
\text { W/ }(\%)\end{array}$}} & \multicolumn{6}{|c|}{ Unit Weight $\left(\mathrm{kg} / \mathrm{m}^{3}\right)$} \\
\hline & & & & W & WSL & $C$ & $F A$ & SF & S \\
\hline Plain & & 0 & 20.0 & 212 & 0 & 743 & 212 & 106 & 1061 \\
\hline$P(-10)$ & & 0 & 18.0 & 195 & 0 & 759 & 217 & 108 & 1084 \\
\hline GA & & \multirow{8}{*}{10} & \multirow{8}{*}{18.0} & 189 & 15 & 736 & 210 & 105 & 1052 \\
\hline LI & & & & 189 & 19 & 741 & 212 & 106 & 1058 \\
\hline LA & & & & 189 & 17 & 739 & 211 & 106 & 1056 \\
\hline ED & & & & 189 & 20 & 742 & 212 & 106 & 1059 \\
\hline HFE & & & & 189 & 32 & 748 & 214 & 107 & 1069 \\
\hline ET & & & & 189 & 17 & 739 & 211 & 106 & 1056 \\
\hline ME & \multirow{2}{*}{$1: 1$} & & & 189 & 17 & 739 & 211 & 106 & 1055 \\
\hline$A C$ & & & & 189 & 17 & 739 & 211 & 106 & 1055 \\
\hline GA & & \multirow{8}{*}{20} & \multirow{8}{*}{16.0} & 189 & 30 & 730 & 209 & 104 & 1043 \\
\hline LI & & & & 189 & 37 & 739 & 211 & 106 & 1055 \\
\hline LA & & & & 189 & 35 & 736 & 210 & 105 & 1051 \\
\hline ED & & & & 189 & 39 & 740 & 212 & 106 & 1058 \\
\hline HFE & & & & 189 & 64 & 754 & 216 & 108 & 1078 \\
\hline ET & & & & 189 & 34 & 735 & 210 & 105 & 1051 \\
\hline ME & & & & 189 & 33 & 735 & 210 & 105 & 1049 \\
\hline$A C$ & & & & 189 & 33 & 735 & 210 & 105 & 1049 \\
\hline
\end{tabular}

$\mathrm{W}:$ water, $\mathrm{L}$ : Non water based liquids $\mathrm{C}:$ cement, FA : fly ash, SF : slilica fume, $S$ : sand
First, to achieve the high strength mortar mixture (plain) with $20 \%$ of water to binder ratio (W/B), we mixed $20 \%$ of fly ash and $10 \%$ of silica by mass ratio. We designed the mixing water for the experiment by replacing it with $10 \%$ or $20 \%$ of 8 different kinds of WSL by volume ratio. $\mathrm{P}(-10), 10 \%$ less than the mixing water for the plain, was added as one more experimental factor.

The plain mixture is designed to meet the target flow of the paste of $220 \pm 10 \mathrm{~mm}$, and a constant mixture proportion by variable was applied to verify its effect.

To confirm fluidity changes, the flow of fresh mortar was measured, and compressive strength, flexural strength and autogenous shrinkage of hardened mortar were also measured, respectively.

\subsection{Materials}

The cement used in this study is ordinary Portland cement manufactured by Korea . Table 3 and 4 illustrate the physical properties of the cement and the fine aggregate, respectively. In terms of the fine aggregate, the river sand from Jochiwon, Chungnam and the crushed sand were mixed at a mixing ratio of $1: 1$.

As for the mineral admixtures, fly ash classified and refined by Korea Midland Power Co., Ltd was used and silica fume from Norway was also used, whose physical properties are shown in Table 5 and Table 6, respectively. The polycarboxylate based superplasticizer produced in Korea whose physical properties are summarized in Table 7 was used.

As one of WSLs, HFE-7100, a liquid for washing electronic devices was used and other WSLs are all the products manufactured and sold in Korea. The physical properties of the WSLs are shown in Table 8.

Table 3. Physical properties of cement

\begin{tabular}{cccccccc}
\hline \multirow{2}{*}{$\begin{array}{c}\text { Density(g/ } \\
\left.\mathrm{cm}^{3}\right)\end{array}$} & $\begin{array}{c}\text { Blaine } \\
\left(\mathrm{cm}^{2} / \mathrm{g}\right)\end{array}$ & $\begin{array}{c}\text { Sound- } \\
\text { ness }\end{array}$ & \multicolumn{2}{c}{$\begin{array}{c}\text { Setting time } \\
(\mathrm{min} .)\end{array}$} & \multicolumn{3}{c}{ Compressive strength(MPa) } \\
\cline { 4 - 8 } & & & Initial & Final & 3 days & 7 days & 28 days \\
\hline 3.15 & 3265 & 0.07 & 232 & 429 & 24.5 & 33.1 & 43.9 \\
\hline
\end{tabular}


Table 4. Physical properties of fine aggregates

\begin{tabular}{cccccc}
\hline Type & Density $\left(\mathrm{g} / \mathrm{cm}^{3}\right)$ & $\begin{array}{c}\text { Fineness } \\
\text { modulus }\end{array}$ & $\begin{array}{c}\text { Absorption } \\
\text { ratio(\%) }\end{array}$ & $\begin{array}{c}\text { Unit } \\
\text { weight } \\
\left(\mathrm{kg} / \mathrm{m}^{3}\right)\end{array}$ & $\begin{array}{c}\text { Passing } \\
\text { amount of } \\
0.08 \mathrm{~mm} \\
\operatorname{sieve}(\%)\end{array}$ \\
\hline $\begin{array}{c}\text { River } \\
\text { sand }\end{array}$ & 2.6 & 2.21 & 0.46 & 1518 & 0.30 \\
$\begin{array}{c}\text { Crushed } \\
\text { sand }\end{array}$ & 2.6 & 3.26 & 0.46 & 1684 & 0.32 \\
\hline
\end{tabular}

Table 5. Physical and chemical properties of fly ash

\begin{tabular}{ccccc}
\hline $\begin{array}{c}\text { Density } \\
\left(\mathrm{g} / \mathrm{cm}^{3}\right)\end{array}$ & $\begin{array}{c}\text { Blain } \\
\left(\mathrm{cm}^{2} / \mathrm{g}\right)\end{array}$ & $\begin{array}{c}\text { L.O.I } \\
(\%)\end{array}$ & $\mathrm{SiO}_{2}$ & $\begin{array}{c}\text { Moisture contents } \\
(\%)\end{array}$ \\
\hline 2.21 & 4061 & 3.5 & 51.2 & 0.01 \\
\hline
\end{tabular}

Table 6. Physical and chemical properties of silica fume

\begin{tabular}{cccccccc}
\hline \multicolumn{2}{c}{$\begin{array}{c}\text { Density Blaine } \\
\left(\mathrm{g} / \mathrm{cm}^{3}\right)\end{array}$} & $(\mathrm{cm} / \mathrm{g})$ & L.O.I(\%) & \multicolumn{5}{c}{ Chemical composition(\%) } \\
\cline { 4 - 7 } & & $\mathrm{SiO}_{2}$ & $\mathrm{Al}_{2} \mathrm{O}_{3}$ & $\mathrm{Fe}_{2} \mathrm{O}_{3}$ & $\mathrm{CaO}$ & $\mathrm{MgO}$ \\
\hline 2.20 & 200 & 1.50 & 96.40 & 0.25 & 0.12 & 0.38 & 0.1 \\
\hline
\end{tabular}

Table 7. Physical and chemical properties of high range water reducing agent

\begin{tabular}{cccc}
\hline Type & Basis & Appearance & $\begin{array}{c}\text { Density } \\
\left(\mathrm{g} / \mathrm{cm}^{3}\right)\end{array}$ \\
\hline $\begin{array}{c}\text { High range water } \\
\text { reducing agent }\end{array}$ & Polycarboxylate Liquid, Dark brown & 1.05 \\
\hline
\end{tabular}

Table 8. Physical properties of WSL

\begin{tabular}{cccc}
\hline WSL & $\begin{array}{c}\text { Density } \\
\left(\mathrm{g} / \mathrm{cm}^{3}\right)\end{array}$ & $\begin{array}{c}\text { Boiling point } \\
\left({ }^{\circ} \mathrm{C}\right)\end{array}$ & Properties \\
\hline Gasoline & 0.71 & $30 \sim 200$ & volatility, hydrophobic \\
Light oil & 0.88 & $250 \sim 350$ & hydrophobic \\
Lamp oil & 0.82 & $180 \sim 250$ & hydrophobic \\
Edible oil & 0.92 & 240 & hydrophobic \\
HFE & 1.52 & 61 & volatility \\
Ethanol & 0.81 & 78.5 & volatility, hydrophilic \\
Methanol & 0.79 & 65 & volatility, hydrophilic \\
Acetone & 0.79 & 56 & volatility, hydrophilic, hydrophobic \\
\hline
\end{tabular}

\subsection{Experimental method}

The mortar was mixed in accordance with KS L 5109, and the flow of fresh mortar was measured according to KS L 5105. The compressive and flexural strength was measured in accordance with ASTM C 348.

To measure the length change due to autogenous shrinkage of hardened cement, we spread a $1 \mathrm{~mm}^{-}$ thick Teflon sheet on the floor and at both sides of the rectangle specimen $(40 \times 40 \times 160 \mathrm{~mm})$ as shown in Figure 1, which allowed the mortar to shrink without any restraint. An embedded strain gauge was installed in the middle of the specimen to measure the autogenous shrink since it was initially set at the data logger.

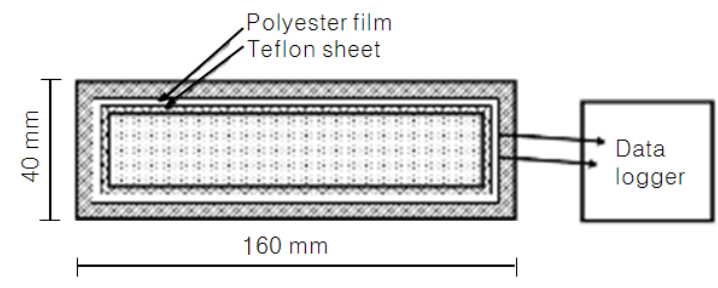

a) plan

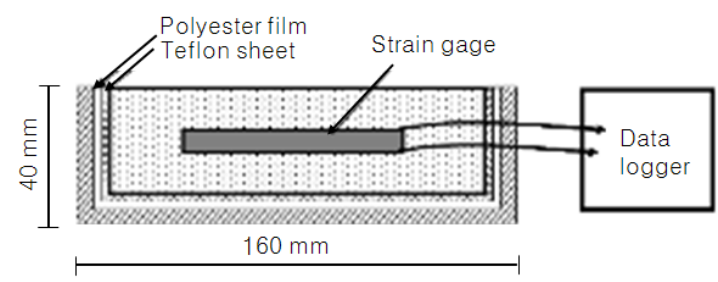

b) longitudinal section

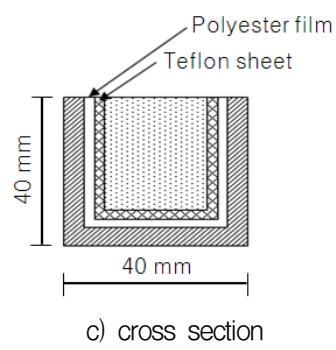

Figure 1. Specimen set up for autogenous shrinkage

At this time, the mortar specimen was removed from the mould after a day elapsed. In order to prevent possible shrinkage or expansion caused by either evaporation or absorption of moisture during the storage, polyester film and aluminum foil were used to wrap the specimen.

Eq. (1) is applied to calculate the change rate of length of autogenous shrinkage by the embedded gauge. In the equation, the coefficient of thermal expansion of the mortar was applied at the time of measurement to offset the shrinkage caused by temperature.

$$
\varepsilon_{3}=\varepsilon_{2}-\Phi \times \Delta t
$$


$\varepsilon_{3}$ : Actual drying shrinkage or change rate of the length of autogenous shrinkage

$\varepsilon_{2}$ : Actual displacement

$\Phi$ : Coefficient of thermal expansion $\left(20.0 \times 10^{-6} /{ }^{\circ} \mathrm{C}\right)$ $\Delta t$ : Temperature difference

\section{Results and Discussion}

\subsection{Fluidity of fresh mortar}

Figure 2 and 3 illustrate the replacement rate of WSL, and the flow by type. First, in terms of flow, plain mixture met the target flow, but $\mathrm{P}(-10)$ was shown to be slightly lower than plain mixture. Overall, the flow values did not show any significant differences among specimens at the $10 \%$ replacement rate. However, the flow values drastically decreased among most specimens at the $20 \%$ replacement rate except for those with ethanol and methanol, which can be interpreted that since the WSLs used in this research have the volatile and hydrophobic properties, which make the fluidity of most specimens reduced greatly.

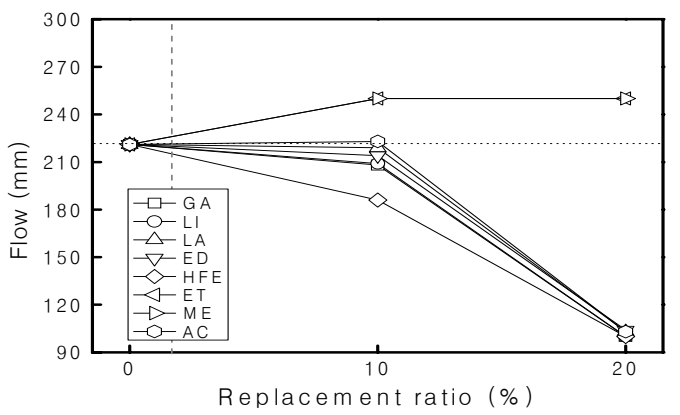

Figure 2. Flow corresponding to WSL kinds and contents

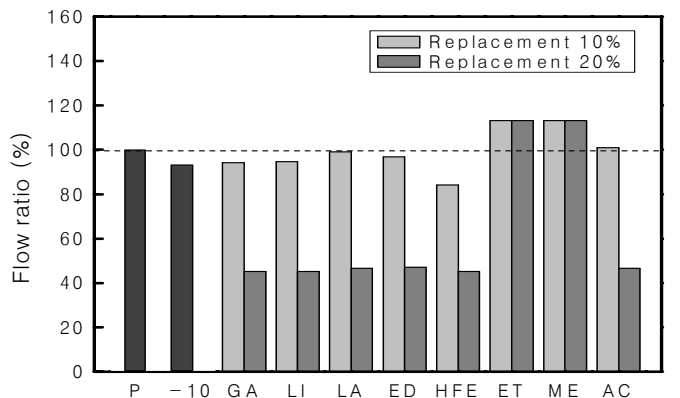

Figure 3. Flow ratio for plain mixture corresponding to various WSL types
The flow was decreased in the order of acetone, lamp oil, edible oil, light oil, gasoline, and $\mathrm{HFE}$ at the $10 \%$ of replacement rate, while the specimens with ethanol and methanol increased compared to plain mixture. In addition, the specimens with ethanol and methanol did not show any decrease in flow compared to plain mixture at the $20 \%$ of replacement rate, while the rest of the specimens showed great decrease in flow compared to plain mixture. It is believed that ethanol and methanol have the polar hydroxyl groups $(-\mathrm{OH})$ in the molecules, and they easily dissolve into the mixing water, which helps regain as much liquid as it was replaced and improve its fluidity as the result[8].

On the other hand, since all kinds of the hydrophobic liquid did not mix well with the specimen, the fluidity seemed to deteriorate. However, acetone has all of hydrophobic, hydrophilic and volatile properties. Therefore, when it is used in a small amount, it turns hydrophilic, but when it is used in a large amount, it turns hydrophobic[9]. It is confirmed that at the $10 \%$ of replacement rate, acetone' $\mathrm{s}$ hydrophilic property helped increase the water demand, and the fluidity improved accordingly, whereas at the $20 \%$ of replacement rate, its hydrophobic property made the fluidity lower greatly.

HFE is usually used as liquid for washing electronic devices due to its strong volatility and making products not getting wet. Its strong volatility and insolubility caused the flow to decrease greatly even at the $10 \%$ of replacement rate.

\subsection{Strength Development}

Figure 4 shows the compressive strength with age by WSL type and replacement rate and Figure 5 illustrates the compressive strength ratio compared to that of plain mixture by age.

First, in terms of the compressive strength, plain mixture had $37 \mathrm{MPa}, 61 \mathrm{MPa}$, and $73 \mathrm{MPa}$ at 1 day, 7 days and 28 days, while $\mathrm{P}(-10)$ had $38 \mathrm{MPa}, 62$ 
$\mathrm{MPa}$, and $75 \mathrm{MPa}$, which showed a slight increase overall compared to that of plain mixture. This may be due to the fact that the decrease in W/B caused by the decreased water demand helped increase the compressive strength.

In terms of strength, the specimens with the $10 \%$ of light oil, HFE, acetone, or edible oil were similar to plain mixture, while the specimens with gasoline and lamp oil as much showed an increase by 8 $\mathrm{MPa} \sim 10 \mathrm{MPa}$ compared to plain mixture. However, the specimens with ethanol and methanol showed a great decrease compared to plain mixture, which may be resulted from the retardation of early cement hydration that alcohol is combined with $\mathrm{Ca}^{2+}$ ions in cement matrix in the process of hydration reaction [8]

On the other hand, in terms of strength, the specimens with the $20 \%$ of gasoline, lamp oil, edible oil and HFE were similar to plain mixture while the specimens with other WSLs decreased by approximately $6 \mathrm{MPa} \sim 32 \mathrm{MPa}$. In addition, although the specimens with ethanol and methanol appeared similar in strength to plain mixture at 7 days, the specimens with other WSLs decreased compared to plain mixture.

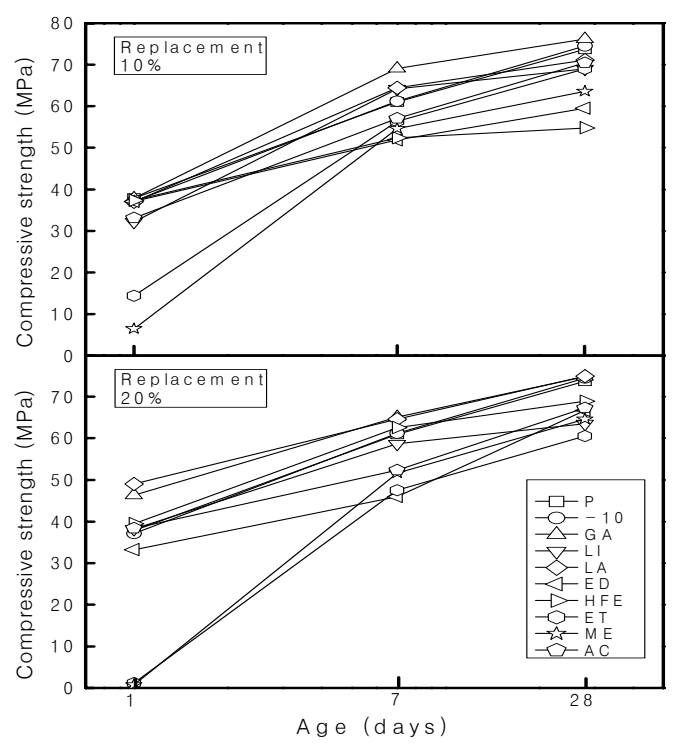

Figure 4. Compressive strength with age

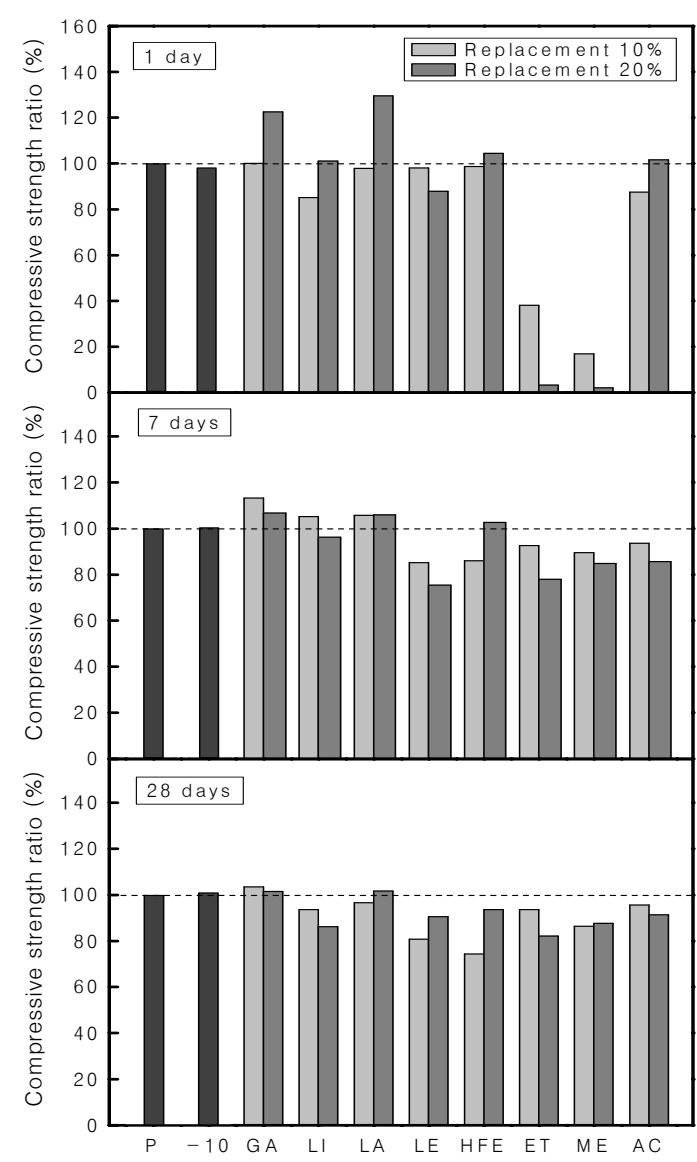

Figure 5. Compressive strength ratio for plain mixture corresponding to WSL kinds and contents

On the other hand, at 28 days the specimens with the $10 \%$ of gasoline and lamp oil showed a slight increase in strength compared to that of plain while the specimens with other WSLs showed a decrease in strength by approximately $6 \mathrm{MPa} \sim 13 \mathrm{MPa}$.

In addition, a similar tendency was shown between at the $10 \%$ and at the $20 \%$ of replacement rate because when water is replaced with one of WSLs, the WSL that has volatile property including gasoline, light oil, lamp oil and HFE vaporizes a little in the fresh mortar, but is captured in the pores in the hardened mortar without being hydrated, which may prevent the WSL from decreasing the W/B. As already reported in the previous study[8,9], ethanol, methanol and acetone that have hydrophilic property and retard strength development barely have the effect on decreasing the W/B. 
Figure 6 shows the flexural strength with age by replacement rate and type of WSL, and Figure 7 illustrates the ratio of flexural strength of the specimen using WSL and plain mixture at 1 day and 28 days, respectively. Plain mixture showed $12 \mathrm{MPa}$ and $27 \mathrm{MPa}$ at 1 day and 28 days, while $\mathrm{P}(-10)$ mixture showed $13 \mathrm{MPa}$ and $23 \mathrm{MPa}$, respectively.

On the other hand, in terms of the flexural strength, the specimens with the $10 \%$ of WSLs except for edible oil, $\mathrm{HFE}$ and ethanol appeared similar to plain mixture. In addition, the specimens with the $20 \%$ of WSLs except for edible oil and HFE also appeared similar to plain mixture, while the specimens with edible oil and HFE decreased by $4 \sim 5$ $\mathrm{MPa}$. The flexural strength tends to be complexly affected by compressive strength, tension and length change of autogenous shrinkage. As shown in the previous study [10], the flexural strength is greatly affected by the autogenous shrinkage. And it is found that the less the autogenous shrinkage, the higher the flexural strength.

\subsection{Autogenous shrinkage of hardened mortar}

Figure 8 shows the results of autogenous shrinkage with age by WSL type and replacement

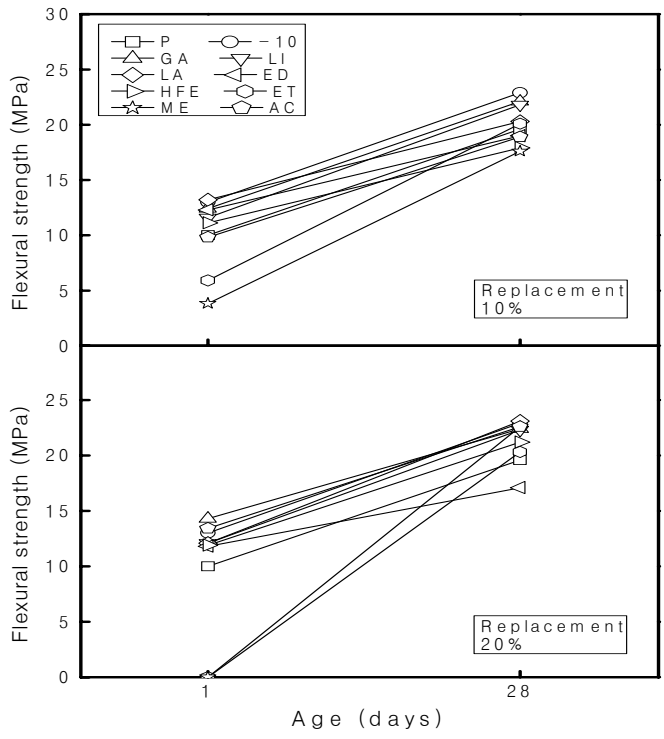

Figure 6. Flexural strength with age

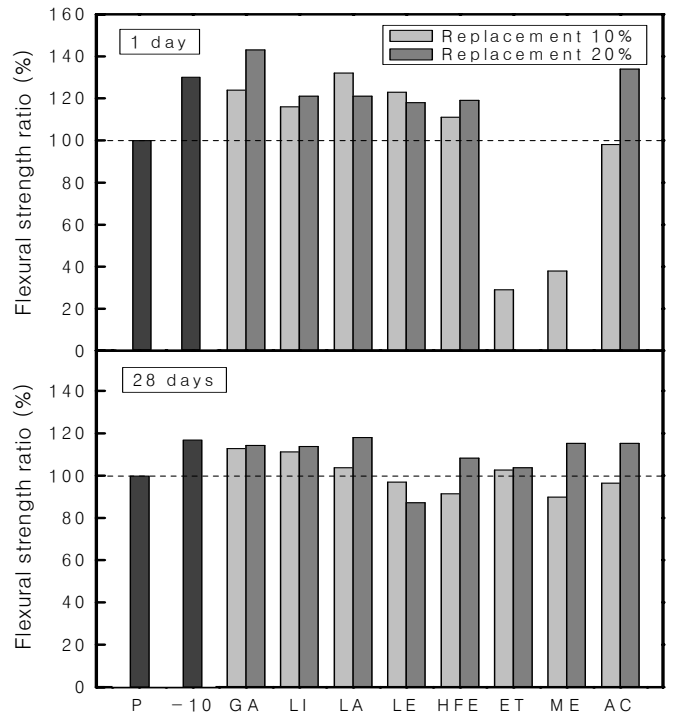

Figure 7. Flexural strength ratio for plain mixture corresponding to WSL kinds and contents

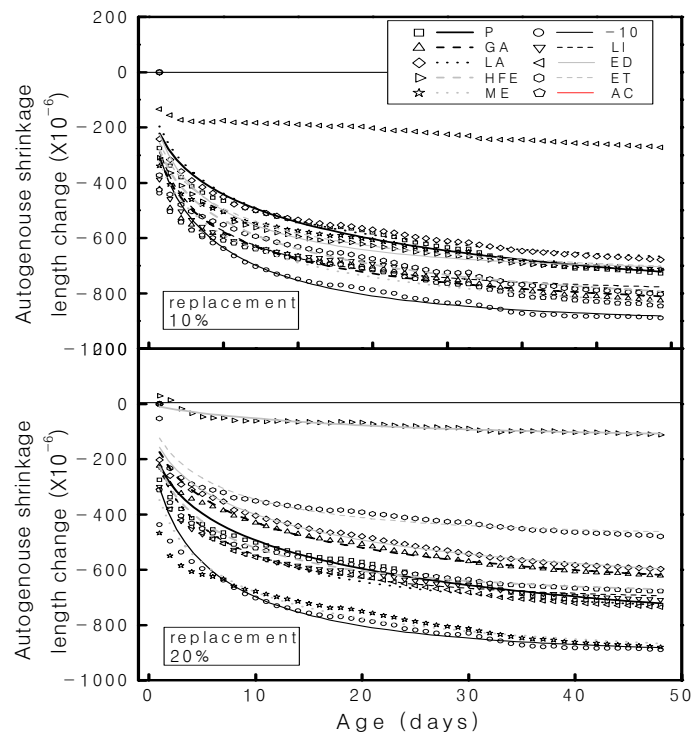

Figure 8. Autogenous shrinkage with age

rate, and the analysis result of the measurements of autogenous shrinkage using the JCI model, and the numerical equation is shown as Eq.(2)[11]. Figure 9 shows the ratio of autogenous shrinkage of the specimens adding WSL and plain mixture at 7, 14 and 49 days. Table 9 shows the results of regression analysis of autogenous shrinkage by the JCI model. 


$$
\varepsilon_{c}(\mathrm{t})=\gamma \cdot \varepsilon_{\infty}(\mathrm{W} / \mathrm{B}) \cdot \beta(\mathrm{t})
$$

where, $\varepsilon_{c}(t)$ : autogenous shrinkage deformation rate at an age of $t$ days $\left(\times 10^{-6}\right)$

$$
\varepsilon_{\infty}(\mathrm{W} / \mathrm{B})=3070 \exp (-7.2(\mathrm{~W} / \mathrm{B}))(0.2 \leq \mathrm{W} / \mathrm{B} \leq 0.5)
$$$$
\beta(\mathrm{t})=1^{-} \exp \left(-\mathrm{a}\left(\mathrm{t}-\mathrm{t}_{0}\right)^{\mathrm{b}}\right)
$$

$\gamma$ : influence coefficient depending on cement and agent

$\mathrm{a}, \mathrm{b}$ : contants depending on W/B

$t_{0}$ : time of initial setting (day)

In terms of autogenous shrinkage, plain mixture was measured at $-728 \times 10^{-6}$ at 49 days, while $\mathrm{P}(-10)$ with a low W/B was measured at $-890 \times 10^{-6}$, which is the highest in value among mixtures.

In terms of the autogenous shrinkage by WSL and replacement rate, the higher the replacement rate, the lower the autogenous shrinkage value. This may be resulted from the residue of WSL within pores of the cement matrix that causes shrinkage reduction and consequently weakens capillarity pressure, or the property that some WSLs tend to retard setting.

What is more notable is that the specimen with the $10 \%$ of edible oil was measured at $-272 \times 10^{-6}$, while

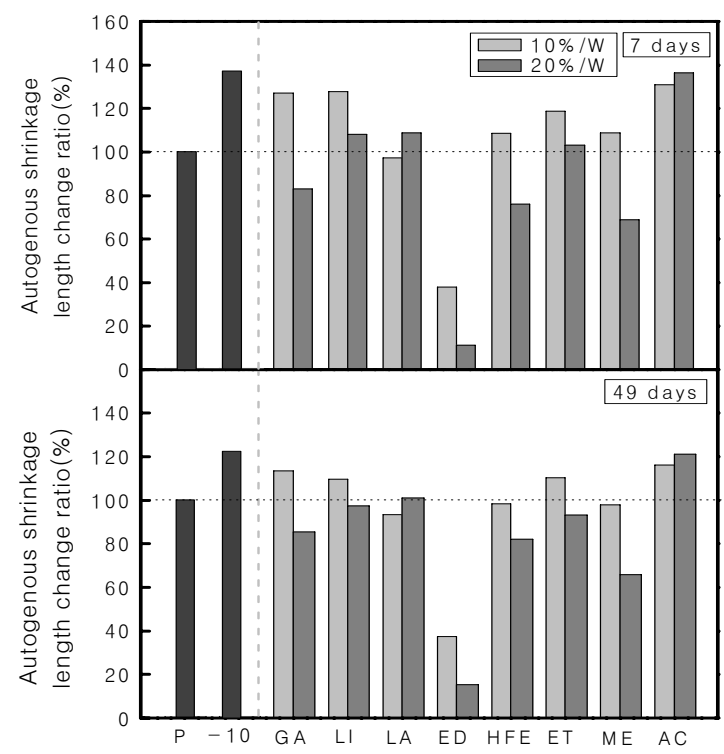

Figure 9. Autogenous shrinkage ratio for plain mixture corresponding to WSL kinds and contents
Table 9. Results of regression analysis for autogenous

\begin{tabular}{|c|c|c|c|c|c|}
\hline \multirow{2}{*}{$\begin{array}{l}\text { Replacement } \\
\text { ratio( } \%)\end{array}$} & \multirow{2}{*}{ Factors } & \multicolumn{4}{|c|}{ Regression coefficients } \\
\hline & & $\gamma$ & $\mathrm{a}$ & $\mathrm{b}$ & $\mathrm{R}^{2}$ \\
\hline \multicolumn{2}{|c|}{ Plain } & 1.256 & 0.279 & 0.445 & 0.927 \\
\hline \multicolumn{2}{|c|}{$P(-10)$} & 1.147 & 0.407 & 0.555 & 0.893 \\
\hline \multirow{8}{*}{10} & GA & 1.101 & 0.445 & 0.459 & 0.853 \\
\hline & $\mathrm{LI}$ & 1.009 & 0.448 & 0.535 & 0.867 \\
\hline & LA & 0.890 & 0.326 & 0.561 & 0.934 \\
\hline & ED & 6.394 & 0.021 & 0.238 & 0.811 \\
\hline & HFE & 0.910 & 0.374 & 0.591 & 0.915 \\
\hline & ET & 1.116 & 0.382 & 0.459 & 0.889 \\
\hline & ME & 0.945 & 0.419 & 0.485 & 0.875 \\
\hline & $A C$ & 1.143 & 0.442 & 0.443 & 0.849 \\
\hline \multirow{8}{*}{20} & GA & 0.762 & 0.286 & 0.518 & 0.943 \\
\hline & LI & 0.775 & 0.391 & 0.568 & 0.905 \\
\hline & LA & 0.832 & 0.364 & 0.538 & 0.916 \\
\hline & ED & 0.135 & 0.084 & 0.819 & 0.915 \\
\hline & HFE & 0.757 & 0.255 & 0.522 & 0.954 \\
\hline & ET & 0.757 & 0.392 & 0.544 & 0.902 \\
\hline & $\mathrm{ME}$ & 0.518 & 0.300 & 0.630 & 0.920 \\
\hline & $\mathrm{AC}$ & 1.011 & 0.466 & 0.448 & 0.836 \\
\hline
\end{tabular}
shrinkage based on $\mathrm{JCl}$ model

the specimen with the $20 \%$ of edible oil at $-105 \times 10^{-6}$, which are 70 80 \% lower in autogenous shrinkage compared to plain mixture. It is believed that the fatty acid, the main ingredient of edible oil, reacted with calcium hydroxide in hardened cement through hydrolysis, and produced calcium salts of fatty acid. Such reactants filled the capillary pores and consequently weakened the capillary pressure that could affect the autogenous shrinkage[12].

From the analytic result of autogenous shrinkage, Table 9 showed the prediced values, which are similar to the measured ones.

In comparison with plain mixture, the specimen with edible oil that showed the best autogenous shrinkage reduction was measured to be $37.4 \%$ and $15.4 \%$ at the $10 \%$ and $20 \%$ of replacement rate, respectively, at an age of 49 days. All the specimens except for those with acetone and lam oil less shrank at the $20 \%$ of replacement rate than at the $10 \%$ of replacement rate.

Figure 10 shows the results of comparative analysis of autogenous shrinkage at $10 \%$ and $20 \%$ of replacement rate. It is found that the higher the replacement rate was, the less autogenous shrinkage 
happened overall.

Figure 11 illustrats the relationship between the compressive strength at 28 days and the autogenous shrinkage value at 49 days. Overall, the higher the compressive strength, the higher the augogenous shrinkage.

As a way of achieving high strength concrete, the repalcement of WSL by the mixing water was studied. In terms of strength, it is hard to expect drastic improvement in strength due to the volatility and retarding property of WSL. However, in terms of autogenous shrinkage of high strength concrete, vegetable oil including edible oil showed a considerable effect on autogenous shrinkage reduction.

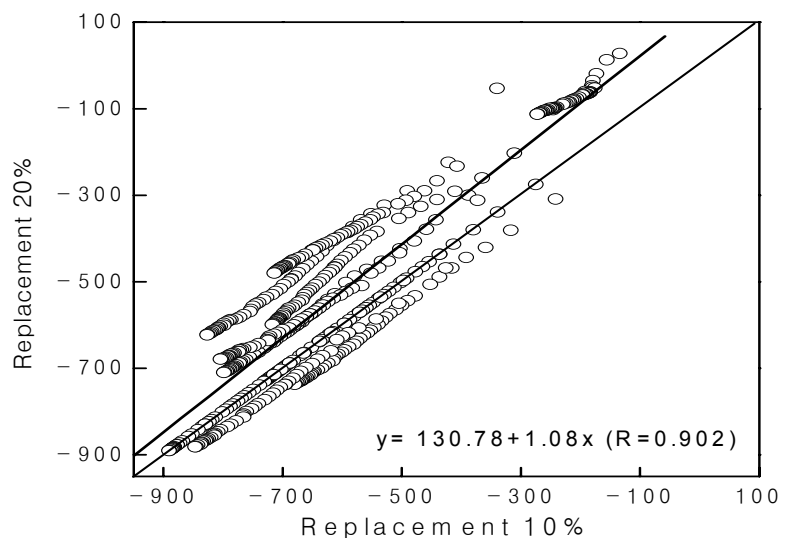

Figure 10. Relationship of replacement ratio of WSL on autogenous shrinkage

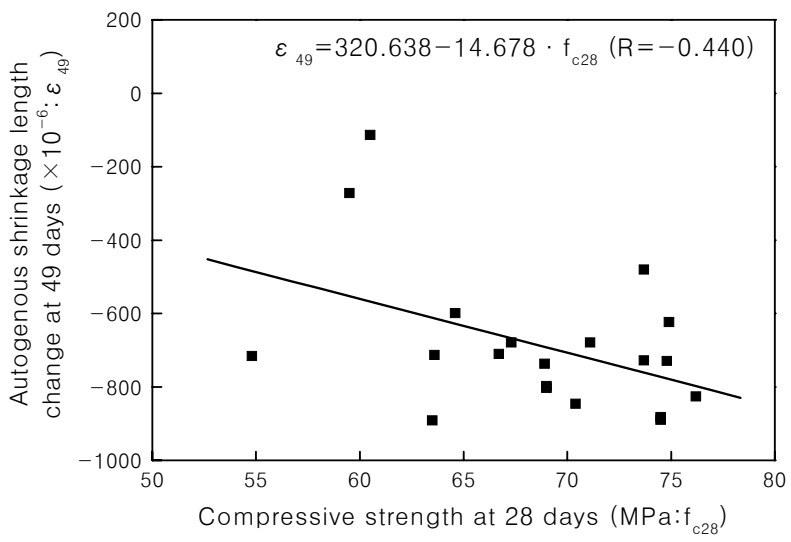

Figure 11. Relationship of autogenous shrinkage and compressive strength

\section{Conclusions}

In this study, tests were conducted to investigate the effect of WSL on the engineering and autogenous shrinkage characteristics of high strength mortar. The results are drawn as follows:

1) In terms of flow, overall specimens were shown to be similar to or slightly lower compared to plain mixture at a $10 \%$ of replacement rate. However, all the specimens except for those with ethanol and methanol were shown to be greatly lower that plain mixture since most of WSL agents were the hydrophobic and were not easily absorbed in mortar.

2) In terms of the compressive strength by WSL type and its replacement rate, all the specimens except for those with methanol and ethanol showed a higher strength than plain mixture at an early age. However, all the specimens except for those with gasoline and lamp oil showed a 10\%-20\% decrease in strength compared to plain mixture at 28 days. It is found that as the compressive strength increased, the flexural strength increased accordingly, standing at 1/3-1/4 of compressive strength.

3) In terms of autogenous shrinkage, as the replacement rate of WSLs increased, the autogenous shrinkage appeared decreasing. It is believed that WSL agents had properties of the shrinkage reduction and retardation of setting.

4) When edible oil (vegetable oil) was replaced, the autogenous shrinkage decreased by $70-80 \%$ compared to plain mixture. It is considered that the fatty acid in the edible oil reacted with calcium hydroxide in hardened cement through saponification. The reactants generated in the reaction filled the capillary pores in the 
hardened mortar and caused capillary pressure to be weakened as a result.

This study was conducted to understand the engineering and autogenous shrinkage characteristics of high strength mortar by replacing some mixing water with WSL for high strength mortar and to ultimately improve concrete properties. Although WSLs barely contribute to improvement of strength, it is confirmed that vegetable oil can be expected to reduce autogenous shrinkage considerably. Further studies should be done to facilitate the vegetable oil to be mixed well with mortar and to reduce the autogenous shrinkage within the extent applicable to practical use in the future.

\section{References}

1. Terauchi R, Hayakawa M, Jinnai H, Watanabe S. Basic study on test age and curing method of specimens for manufacturing control of high strength concrete. Journal of Structural and Construction Engineering. 2008 Nov;73(633):1899-1906.

2. Yang DI, Kim JM, Gong MH, Jung SJ. An Experimental Study For Basic Property of Ultra High Strength Concrete. Journal of the Architectural Institute of Korea. Structure \& Construction. 2006 Sep;22(9):99-106.

3. Han CG, Han MC, Lee DG. Added AE Water Reducing Agent on Physical Properties of the Concrete, Journal of The Korea Institute of Building Construction, 2008 Feb;2(27):91-6.

4. Lee JG, Park KS, Kim SY, Jang MG, Kim HJ. The Fundamental Study on the decision of the weight of water required to cement hydration. Proceedings of The Korean Society of Agriculture Engineers Conference; 2000 Oct. Seoul (Korea): The Korean Society of Agriculture Engineers; 2000. p. $266-71$

5. Kang H, Ahn JM, Shin SW. Mechanical and Mixing Properties of Ultra-high Strength Concrete with fck=150MPa. Journal of the Korea Institute of Building Construction. $2010 \mathrm{Mar}$;10(3):113-20.

6. Han CG, Hwang YS, Kim KS, Kim YD. Influence of Unit Water Content on the Durability and Properties of Fresh Concrete. Journal of the Architectural Institute of Korea. Structure \& Construction. 2003 Apr;19(4):129-36.

7. 3M, Novec 71DA Engineered Fluid, Product Information.
Electronics Markets Materials Division, from:http://solutions.3 m.com/wps/portal/3M/en_US/MSDS/Search/?gsaAction=msds SRA\&type $=$ p\&snum $=10 \&$ type $=$ p\&co $=$ ptn\&msdsLocale $=$ en_us\& $\mathrm{q}=$ novec\&num $=10 \&$ start $=20$

8. Kang SM, Kang HJ, Song MS, Park PH. A Study on the Early Hydration-Retarding Mechanism of Polymer Modified Cement. Proceedings of the Korea Concrete Institute; 2009 may 29; Hanyang university. Seoul (Korea): Korea Concrete Institute; 2009. p. 221-2.

9. Park CW, Kim HD. Graft Copolymerization of Methyl Methacrylate on Sodium Alginate in the Acetone-Water Solution of Various Compositions by Hydrogen Peroxide (II), Polymer(Korea), 1982 Oct;6(5):294-304.

10. Safat A, Gianluca R, Zora V. Shrinkage effects on the flexural stiffness of composite beams with solid concrete slabs: An experimental study. Engineering Structures. 2011 April;33 (4):1302-15.

11. Ei-ichi T, Shingo M. Prediction Model for Shrinkage of Concrete Including Autogenous Shrinkage, Proceedings of Sixth International Conference; in: F.-J. Ulm, Z.P. Bazant, F.H. Wittmann, Editors, Creep, Shrinkage and Durability Mechanics of Concrete and Other Quasi-Brittle Materials.: Elsevier Science Ltd,; 2001. p. 735-46.

12. Lee CS, Pack JH. Relation between Autogenous Shrinkage of Concrete and Relative Humidity, Capillary Pressure, Surface Energy in Pore, Journal of the Korea Concrete Institute. 2008 Apr;20(2):131-8. 